\title{
Research Status and Prospect of Seepage Erosion in Foundation Pit Engineering
}

\author{
Hongliang LIU ${ }^{\mathrm{a}}$, Xinjiang WEI ${ }^{\mathrm{b}}$, Lisha ZHANG ${ }^{\mathrm{b}, 1}$ and Chang XIA ${ }^{\mathrm{c}}$ \\ ${ }^{a}$ School of Civil Engineering Architecture, Zhejiang University, Hangzhou 310058, \\ China \\ ${ }^{\mathrm{b}}$ College of Engineering, Zhejiang University City College, Hangzhou 310015, China \\ ${ }^{\mathrm{c}}$ Fuzhou Planning \& Design Research Institute Group Co., Ltd., Fuzhou 350108, \\ China
}

\begin{abstract}
In water-rich strata, the distribution of groundwater is complicated. Construction projects related to foundation pit engineering in such areas are prone to cause piping failure, fluid soil failure, and other seepage-related failures. Seepage erosion is a kind of seepage failure that occurs inside the soil. Because the process is difficult to observe and measure, seepage erosion is rarely considered in the current foundation pit engineering. This article analyzes the relevant research on seepage erosion, and further clarifies the influence of seepage erosion on soil characteristics. In addition, this article puts forward some suggestions for the shortcomings of the current research on erosion, and made some prospects for future research on erosion in foundation pit engineering, hoping to provide theoretical guidance and thinking inspiration for future research.
\end{abstract}

Keywords. Seepage erosion, foundation pit engineering penetration, permeability coefficient, soil grain structure, deformation of soil

\section{Introduction}

With the rapid development of China's economy and the continuous advancement of the urban construction process, the number of foundation pit engineering projects in coastal areas has been increasing in recent years. For example, in Hangzhou, the depth of the Hangzhou Center foundation pit currently under construction has a depth of 34.6 meters, setting the record for the deepest foundation pit in Zhejiang Province. By the 19th Asian Games Hangzhou 2022, Hangzhou will add 6 new river-crossing tunnels.

The design and construction of foundation pits are closely related to the geological conditions, especially in the water-rich stratum, where the hydrogeological conditions are very complicated. If groundwater isn't treated properly, it is easy to cause engineering accidents such as piping failure, fluid soil failure, supporting structures failure, and even collapse of foundation pits [1]. As a kind of soil seepage failure, seepage erosion changes soil properties and structure [2], which will bring great security risks to the engineering construction project. According to incomplete statistics, $37 \%$ of the well-known dam deformation and collapse accidents in the world are caused by soil seepage erosion [3], such as the local settlement accident of Esfarayen

\footnotetext{
${ }^{1}$ Lisha Zhang, College of Engineering, Zhejiang University City College, Hangzhou 310015, P.R. China; E-mail: zhangls@zucc.edu.cn.
} 
Dam [4]. Under the background of frequent soil erosion and increasing attention to the safety management of foundation pits, this paper introduces the issue of soil seepage erosion into foundation pit engineering to explore its mechanism and impact on foundation pit engineering, to provide a reference for future theoretical research and engineering practice.

\section{Seepage Erosion Mechanisms}

Starting from the basic theories of seepage erosion, combined with current seepagerelated experimental researches carried out by many scholars, as well as the present seepage erosion calculation models, to grasp the seepage erosion mechanism.

\subsection{Basic Theories}

Two conditions must be met for soil seepage erosion: (1) Hydraulic conditions. Under the action of seepage, the fine particles in the soil will break through the existing mechanical equilibrium and migrate. (2) Geometric conditions. The fine particles in the soil can migrate through pore channels formed between coarse particles in the soil.

\subsubsection{Hydraulic Conditions}

Hydraulic conditions are the necessary condition for soil seepage failure. Therefore, Terzaghi et al. [5], Wu [6], and Mao et al. [7] have done a lot of research. In addition, Wang et al. [8] established the stress models of the soil fine particles in the seepage field based on the effective stress of the soil and the stress-reduction of fine particles.

The research [8] has shown that the critical hydraulic gradient is related to soil characteristics, permeable water flow, particle buried depth and particle size, etc., and the critical hydraulic gradient is different when fine particles migrate in different directions. When the depth of the soil is deeper, the critical hydraulic gradient required for the initiation of seepage is nothing to do with the soil particles characteristics.

\subsubsection{Geometric Conditions}

In order for the soil fine particles to move through the pores between the coarse particles, their particle size must be smaller than the pore channel diameter. Jiang et al. [9], Cai et al. [10], Marot et al. [11], and Fujisawa et al. [12] have analyzed the stability of the internal structure of the soil when seepage occurs from the perspectives of the particle size distribution, pore distribution, particle shape, and soil pore diameter.

The above research results have shown that the internal seepage erosion of soil is closely related to the properties of the soil itself, that is, the soil properties determine the geometric conditions of the pipes inside the soil structure.

\subsection{Experimental Researches}

Carry out experimental researches to study the characteristics of soil seepage erosion, and further explore the seepage erosion mechanisms.

By manufacturing or modifying the test device, the influence of vertical stress [13], the soil triaxial compressive stress state [14], the seepage hydraulic gradient [15], the 
coarse and fine grain content of the soil [16] on the process of soil seepage erosion is fully considered. Liang et al. [17] designed a new hydraulic mechanical coupling erosion test to analyze the influence of deviatoric stress on the balance of particles in soil under isotropic stress state and anisotropic stress state. Except for model tests, Stewart et al. [18] also used computed tomography to observe the internal piping erosion of the dam. Masoodi et al. [19] used Kinect high-speed photogrammetry technology to obtain high-precision spatial resolution data, which can analyze the degree of erosion within the soil.

Current experimental researches provide new ideas for the study of seepage erosion in foundation pit engineering. We can modify and improve the existing test equipment to make it more suitable for the study of seepage erosion problems. In addition, the research technology in other fields such as optics can be applied to foundation pit engineering to promote the development of the research on the seepage erosion.

\subsection{Calculation Models}

Based on the existing experimental research results, scholars have established many calculation models for the study of seepage erosion by setting relevant parameters, and conducted a lot of research on the process of seepage erosion. Current main calculation models include stochastic model [20], well flow model [21], fine particle migration model [22], permeability finite element model [23], capillary-tube model [24], particle flow model [25], seepage and pipe flow coupling model [26], and elastoplastic constitutive model of soil which is suitable for the study of the impact of mechanical behavior in the process of soil seepage erosion. [27].

With the continuous improvement of the calculation models, we can simulate the influence of seepage diameter, seepage hydraulic gradient, and soil properties on seepage. What's more, the calculation models can dynamically monitor the migration of soil fine particles and the evolution of soil structure during the seepage process and realize the quantitative simulation of the seepage erosion process from macros to micro.

Current seepage erosion studies are often carried out for the micro research of soil elements, which is in the stage of theoretical research and is rarely applied to the macro actual engineering situation. Therefore, there is a great development space to explore the problem of seepage erosion in foundation pit engineering.

\section{Influence of Seepage Erosion on Foundation Pit Engineering}

Seepage erosion will cause the fine particles of the soil to migrate in the pore channels, which will change the soil structure and cause the soil deformation.

\subsection{The Change of Soil Permeability Coefficient}

In the foundation pit engineering, we often consider that the soil permeability coefficient remains unchanged. But related studies [28] indicate that when the hydraulic gradient is large, the permeability coefficient changes abruptly. Therefore, the permeability coefficient should be corrected in the seepage calculation of foundation pit engineering. 
According to the Kovacs permeability coefficient formula [29] and other permeability coefficient studies [24,30], we can know that seepage erosion will cause fine particles to migrate with the water flow, forming a silting structure locally to block the pore channels of the soil, as shown in figure 1, and then resulting in a decrease in the local soil permeability coefficient. With the decrease of the permeability coefficient, the impermeability of the foundation pit soil will be enhanced, which will be more conducive to the stability of the foundation pit. When the permeability coefficient increases, the impermeability will decrease, which will easily lead to the collapse of foundation pit engineering. In order to improve the safety of foundation pit engineering, it is necessary to strengthen the research of seepage erosion in foundation pit engineering and select reasonable soil calculation parameters according to the actual engineering situation.

\subsection{The Influence on Soil Deformation}

The soil deformation caused by seepage erosion mainly originates from two aspects: The macro seepage force produces downward compaction or upward supporting effect on the soil, causing soil deformation. The micro seepage erosion changes soil structure, causing soil particle rearrangement and stress redistribution to cause soil deformation.

\subsubsection{Soil Deformation under Macro Seepage Force}

Seepage force is also a kind of volume force like gravity, and it's triangularly distributed in the soil along the direction of the seepage streamline [31]. Therefore, when downward seepage occurs, seepage force is the same as gravity, which has a compacting effect on the soil. When upward seepage occurs, seepage force is opposite to the direction of gravity, which has an upward supporting effect on the soil.

In foundation pit engineering, because the groundwater level inside the foundation pit is lower than the outside, seepage will occur from the outside of the foundation pit to the inside. The streamline distribution generally starts from the active zone going down to the bottom of the supporting structure and then going up to the top of the passive zone. Therefore, under the action of seepage force, the soil in the active zone will settle and the soil in the passive zone will uplift.

\subsubsection{The Change of Soil Structure Causes Soil Deformation}

Seepage erosion causes fine particles to migrate in the soil under the action of seepage, and causes the soil framework to become loose or dense [32]. It is mainly manifested in the changes in soil density and porosity, as shown in figure 2.

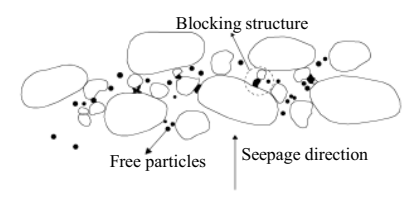

Figure 1. Schematic diagram of free particle migration

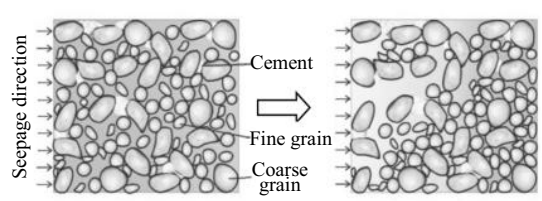

Figure 2. Schematic diagram of fine particle migration effect by seepage erosion. 
Under the action of seepage erosion, the fine particles will be stripped from the soil skeleton by water flow and converted into liquefied particles with water movement. The density of the liquefied particles satisfies the mass conservation equation [22], and the soil skeleton density control equation [33] is obtained through mass conservation, and then the governing of foundation pit soil porosity [33] under seepage erosion is obtained.

It can be concluded from the above studies that seepage erosion causes the fine particles to move from behind the seepage to the front, and then deposit. This cause the local soil structure to become loose or dense, and changes the soil density and porosity. Under the constant upper pressure, the soil stress is redistributed, causing soil deformation $[3,34]$. The above conclusions have been confirmed by Chen et al. [35].

The migration of fine particles will affect the soil skeleton density, porosity, and soil structure of the local soil, increasing the risk of soil deformation. In addition, Yao et al [32] carried out a micro seepage test, and obtained the curve of the surface settlement of the sample and the loss of movable fine particles with time, as shown in figure 3. It can be seen that with the loss of fine soil particles, the surface settlement of the sample gradually increases. Qian et al. [36] took a foundation pit project in a deep saturated soft soil area in Nanjing to conduct a systematic analysis of groundwater seepage factors on foundation pit deformation data. As shown in figure 4, the results show that after considering seepage erosion, the surface settlement increased significantly.

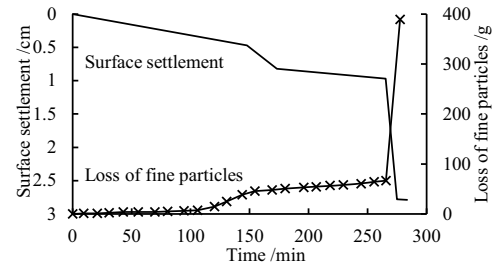

Figure 3. Surface settlement and eroded particles at the different times [32].

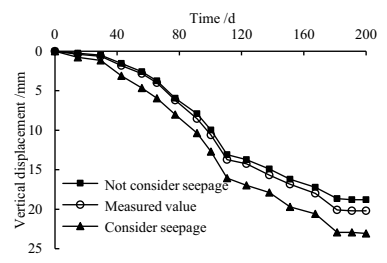

Figure 4. Settlement curves of a point outside the excavation [36].

Soil seepage erosion can change soil characteristics and structure, affect the local soil stability, and cause local soil deformation, which are related to the safety and quality of engineering construction. Therefore, it is urgent to carry out research on seepage erosion and control its impact on foundation pit engineering through technical means.

\section{Conclusion and Prospects}

This article analyzes and summarizes the current seepage erosion studies, explores the impacts of seepage erosion on foundation pit engineering, and proposes some suggestions for the current research. The conclusions and prospects are as follows.

(1) When seepage erosion occurs in the soil, hydraulic and geometric conditions must be met. The existing calculation models realize the quantitative simulation of the process from macro to micro, they can simulate and monitor the influence of multiple factors during the soil seepage process. 
(2) Seepage erosion will cause fine particles to migrate along the infiltration direction and deposit in the area in front of the infiltration, which will change local pore channels, soil skeleton structure, density, and porosity, even cause the rearrangement of soil particles and the redistribution of soil stress, and cause soil deformation under the combined action. And under the action of seepage forces in different directions, the soil will undergo downward compaction or upward support to cause soil deformation.

(3) In foundation pit engineering, the change of soil permeability coefficient is related to the stability of foundation pit soil, and soil deformation will cause safety hazards to the foundation pit project and surrounding buildings. Therefore, the seepage erosion should be fully considered during the foundation pit design and construction.

(4) The future research of foundation pit engineering will focus on the seepage erosion mechanisms, including the improvement of scientific test methods, and advanced calculation models. Future research will realize the transition from microresearch to macro-application, fully apply the research results to actual projects, and improve the accuracy and safety of the design and construction process.

\section{Acknowledgments}

The research is funded by the National Natural Science Foundation of China (Nos. 52078466, 51808492), Zhejiang Provincial Public Welfare Science and Technology Application Research Project (No. LGG21E080003), Zhejiang Provincial Natural Science Foundation of China (No. LY18E080026), China Postdoctoral Science Foundation (No. 2021M690883), Research Funds for Hangzhou science and Technology Committee (No. 20201203B144), and Fundamental Research Funds for the Central Universities, Key Laboratory of Western China's Mineral Resource and Geological Engineering, Ministry of Education, Chang'an University (Nos. 300102260505, 300102260201).

\section{References}

[1] Yang JM, Zheng G. Classification of seepage failures and opinion to formula for check bursting instability in dewatering. Rock and Soil Mechanics. 2009 Jan; 30(1): 261-264.

[2] Hunter RP, Bowman ET. Visualization of seepage-induced suffusion and suffusion within internally erodible granular media. Geotechnique. 2018 Oct; 68(10): 918-930.

[3] Chang DS. Internal erosion and overtopping erosion of earth dams and landslide dams. Hong Kong: The Hong Kong University of Science and Technology. Department of Civil and Environment Engineering. 2012 Jun.

[4] Razavi SK, Bonab MH, Dabaghian A. Investigation into the internal erosion and local settlement of Esfarayen earth-fill dam. Journal of Geotechnical and Geoenvironmental Engineering. 2020 Apr; 146(4): 040200064.

[5] Terzaghi K, Peck RB. Soil mechanics in engineering practice. In: 3rd, Editors. Drained shear strength 19.New York: John Wiley and Sons Inc; 1996. p. 149-150.

[6] Wu LJ. Computation of the critical hydraulic gradient for piping of non-cohesive soil. Journal of Nanjing Hydraulic Research Institute. 1980 Dec; (4): 90-95.

[7] Mao CX, Duan XB, Wu LJ. Study of critical gradient of piping for various grain sizes in sandy gravels. Rock and Soil Mechanics. 2009 Dec; 30(12): 3705-3709.

[8] Wang MN, Jiang YT, Yu Li, et al. Analytical solution of starting critical hydraulic gradient for fine particles of sandy soil. Rock and Soil Mechanics. 2020 May; 41(8): 2515-2524.

[9] Jiang Y, Jiang H. Researches on filling coefficients for stability of soil stratum permeability. Chinese Journal of Geotechnical Engineering. 2006 Mar; 28(3): 372-376. 
[10] Cai YQ, Zhang ZX, Cao ZG, et al. Mesoscopic numerical simulation for suffusion process of gapgraded sandy soil. Journal of Central South University 2019 May; 50(5): 1144-1153.

[11] Marot D, Bendahmane F, Bguyen HH. Influence of angularity of coarse fraction grains on internal erosion process. In: Paplorey C, La Houille Blanche; Paris, Eur: 2012. p.47-53.

[12] Fujisawa K, Murakami A, Nishimura SI. Numerical analysis of the erosion and the transport of fine particles within soils leading to the piping phenomenon. Soils and Foundations. 2010 Aug; 50(4): 471482.

[13] Moffat RA, Fannin RJ. A large permeameter for study of internal stability in cohesionless soils. Geotechnical Testing Journal. 2006 Apr; 29(4): 273-279.

[14] Bendahmane F, Marot D, Alexis A. Experimental parametric study of suffusion and backward erosion. Journal of Geotechnical and Geoenvironmental Engineering. 2008 Jan; 134(1): 57-67.

[15] Lourenco SDN, Wang GH, Chu J. Aspects of sand behaviour by modified constant shear drained tests. Environmental Earth Sciences. 2011 Feb; 62(4): 865-870.

[16] Shen H, Luo XQ, Bi JF. Numerical simulation of internal erosion characteristics of block in matrix soil aggregate. Rock and Soil Mechanics. 2017 May; 38(5): 1497-1513.

[17] Liang Y, Yeh TCJ, Wang JJ. Onset of suffusion in upward seepage under isotropic and anisotropic stress conditions. European Journal of Environmental and Civil Engineering. 2019 Dec; 23(12): 15201534.

[18] Stewart RA, Garner SJ. Performance and safety of WAC bennet dam-a seven year update. Proceeding 53rd Canadian Geotechnical Conference. 2002 Jun; 2(30): 97-106.

[19] Masoodi A, Noorzad A, Tabatabai MRM, et al. Application of short-range photogrammetry for monitoring seepage erosion of riverbank by laboratory experiments. Journal of Hydrology. 2018 Mar; 558: 380-391.

[20] Luo YL, Su BY, Sheng JC, et al. New understandings on piping mechanism. Chinese Journal of Geotechnical Engineering. 2011 Dec; 33(12): 1895-1902.

[21] Mao CX, Duan XB, Cai JB, et al. Theoretical analysis on piping development of levee foundation. Shuili Xuebao. 2004 Dec; 35(12): 46-50.

[22] Cividini A, Gioda G. Finite element approach to the erosion and transport of fine particles in granular soils International Journal of Geomechanics. 2004 Aug; 4(3): 191-198.

[23] Ding LQ, Wu MX, Liu CJ, et al. Numerical simulation of dynamic development of piping in two stratum dike foundations. Water Resources and Hydropower Engineering. 2007 Feb; 38(2): 36-39.

[24] Liu ZY, Yue JC, Miao TD. Capillary-tube model for piping in non-cohesive soils and its application. Chinese Journal of Rock Mechanics and Engineering 2004 Nov; 23(22): 3871-3876.

[25] Zhou J, Yao ZX, Zhang G. Research on piping mechanism in sandy soils based on discrete element theory. Chinese Journal of Rock Mechanics and Engineering. 2008 Apr; 27(4): 749-756.

[26] Zhou XJ, Jie YX, Li GX. Numerical simulation of piping based on coupling seepage and pipe flow. Rock and Soil Mechanics. 2009 Oct; 30(10): 3154-3158.

[27] Yang J, Yin ZY, Laouafa F, et al. Hydromechanical modeling of granular soils considering internal erosion. Canadian Geotechnical Journal. 2020 Feb; 57(2): 157-172.

[28] Jiang ZM, Wang W Feng SR, et al. Experimental study on influence of stress state on seepage failure characteristics of coarse grained soil with cohesive particles. Chinese Journal of Geotechnical Engineering. 2014 Jan; 36(1): 98-105.

[29] Kovacs G. Seepage Hydraulics[M].In: 1st, editors. Amsterdam Oxford New York Elsevier Scientific Publishing Company; 1981 Jan.

[30] Sato M, Kuwano R. Suffusion and clogging by one-dimensional seepage tests on cohesive soil. Soils and Foundations. 2015 Dec; 55(6): 1427-1440.

[31] Liu J, Fu Y. Permeability and compaction properties of soil. Shuili Xuebao. 1993 May; (5): 76-81.

[32] Yao ZX, Zhou J, Zhang G. Meso-experimental research on piping mechanism in sandy soils. Rock and Soil Mechanics. 2009 Jun; 30(6): 1604-1610.

[33] Papamichos E, Vardoulakis I. Sand erosion with a porosity diffusion law. Computers and Geotechnics. 2004 Jun; 32(1): 47-58.

[34] Tomlinson SS, Vaid YP. Seepage forces and confining pressure effects on piping erosion. Canadian Geotechnical Journal. 2000 Feb;37(1):1-13.

[35] Chen C, Zhang LM, Chang DS. Stress-Strain Behavior of Granular Soils Subjected to Internal Erosion. Journal of Geotechnical and Geoenvironmental Engineering. 2016 Dec; 142(12): 06016014.

[36] Qian DL, Li JC, Liu GC, et al. Deformation analysis on foundation pit excavation based on seepage effect. Journal of Nanjing Tech University (Natural Science Edition). 2015 Jan; 37(1): 81-87. 